\title{
ANALISIS FAKTOR-FAKTOR YANG MEMPENGARUHI PETERNAK SAPI POTONG TERHADAP INTENSITAS PENGGUNAAN INSEMINASI BUATAN DI KECAMATAN KENDIT KABUPATEN SITUBONDO
}

\author{
Daniel Kristiawan Suteja \\ Program Studi Agribisnis, Fakultas Pertanian, Universitas Abdurachman Saleh Situbondo \\ Email Korespondensi : danielks@gmail.com
}

\begin{abstract}
Abstrak
Upaya yang dapat dilakukan untuk meningkatkan populasi sapi potong adalah dengan menerapkan inseminasi buatan pada sapi potong. Selama ini dalam aplikasi teknologi IB umumnya spermatozoa yang dimanfaatkan adalah hasil ejakulasi yang ditampung dengan vagina buatan. Agar dapat mencapai tujuan suatu program Inseminasi Buatan maka penggunaan pejantan yang bebas penyakit dan bermutu genetik tinggi secara maksimal, dengan kemampuan fertilisasi optimum, spermatozoa harus diawetkan agar dapat digunakan untuk beberapa waktu yang lama sehingga dapat dijual pada waktu yang lainnya. Untuk itu semen perlu dicampur dengan larutan pengencer yang menjamin kebutuhan fisik dan kimiawinya. Hal yang dapat dilakukan untuk meningkatkan produksi daging salah satunya melalui inseminasi buatan. Inseminasi buatan adalah teknologi perkembangbiakan yang mempunyai banyak keuntungan. Selain biaya yang terjangkau, Inseminasi Buatan juga mengurangi tingkat resiko kematian akibat kecelakaan yang terjadi dalam proses perkawinan alami. Inseminasi Buatan juga mempunyai manfaat yang penting yaitu meningkatkan mutu benih. Sperma yang digunakan untuk Inseminasi adalah sprema yang memiliki kualitas terbaik. Faktor-faktor yang mempengaruhi peternak sapi potong di Kecamatan Kendit dalam penggunaan Inseminasi Buatan yaitu umur, pendidikan terakhir, jumlah keluarga, intensitas penyuluhan, dan pengalaman beternak sebesar 68,1\%, sedangkan sisanya 31,9\% dipengaruhi oleh variabel-variabel lain yaitu keberhasilan Inseminasi Buatan dan pelayanan Inseminator yang tidak dimasukkan dalam model regresi.
\end{abstract}

Kata Kunci : Sapi Potong, Inseminasi Buatan (IB), Kecamatan Kendit

\begin{abstract}
Efforts that can be made to increase the population of beef cattle are by applying artificial insemination to beef cattle. During this time in the application of IB technology, generally the spermatozoa that are utilized is the result of ejaculation that is accommodated with an artificial vagina. In order to achieve the goal of an Artificial Insemination program, the maximum use of disease-free and high-quality genetic males, with optimum fertilization capabilities, must be preserved so that it can be used for a long time so that it can be sold at other times. For this reason cement needs to be mixed with a diluent solution that guarantees its physical and chemical needs. One thing that can be done to increase meat production is through artificial insemination. Artificial insemination is a breeding technology that has many advantages. In addition to affordable costs, Artificial Insemination also reduces the risk of death due to accidents that occur in the natural marriage process. Artificial Insemination also has important benefits, namely improving seed quality. The sperm used for insemination is the sperm that has the best quality. Factors that influence beef cattle farmers in Kendit Subdistrict in the use of Artificial Insemination are age, recent education, number of families, intensity of counseling, and farming experience of $68.1 \%$, while the remaining $31.9 \%$ is influenced by other variables namely success Artificial Insemination and Inseminator services not included in the regression model.
\end{abstract}

Keywords: BeefCattle, Artificial Insemination (IB), Kendit District 


\section{PENDAHULUAN}

Peternakan merupakan salah satu subsektor pertanian yang berperan penting dalam mewujudkan pembangunan ketahanan pangan nasional. Subsektor peternakan memiliki andil dalam menjaga ketersediaan pangan dan kecukupan gizi bagi masyarakat Indonesia. Pembangunan sektor peternakan merupakan bagian dari pembangunan pertanian yang bertujuan untuk mencapai kondisi peternakan yang tangguh, memiliki kemampuan untuk mensejahterahkan para peternak, dan kemampuan mendorong pertumbuhan sektor terkait secara keseluruhan. Namun pembangunan sektor peternakan harus diimbangi dengan peningkatan produksi dan populasi ternak sapi potong.

Upaya yang dapat dilakukan untuk meningkatkan populasi sapi potong adalah dengan menerapkan inseminasi buatan (IB) pada sapi potong. Selama ini dalam aplikasi teknologi IB umumnya spermatozoa yang dimanfaatkan adalah hasil ejakulasi yang ditampung dengan vagina buatan (Toelihere dalam Idfar, 2017). Agar dapat mencapai tujuan suatu program IB (Inseminasi Buatan) maka penggunaan pejantan yang bebas penyakit dan bermutu genetik tinggi secara maksimal, dengan kemampuan fertilisasi optimum, spermatozoa harus diawetkan agar dapat digunakan untuk beberapa waktu yang lama sehingga dapat dijual pada waktu yang lainnya. Untuk itu semen perlu dicampur dengan larutan pengencer yang menjamin kebutuhan fisik dan kimiawinya.

Kementerian Pertanian meluncurkan program Upsus Siwab (Upaya Khusus Sapi Wajib Bunting). Program ini bertujuan untuk mempercepat peningkatan populasi sapi potong dalam negeri dan mampu mewujudkan swasembada sapi yang ditargetkan akan dicapai pada tahun 2026 serta pemenuhan kebutuhan pangan asal hewan dan sekaligus meningkatkan kesejahteraan rakyat. Upsus Siwab mencakup dua program utama yaitu peningkatan populasi melalui Inseminasi Buatan dan Intensifikasi Kawin Alam. (Anonim, 2016)

\section{METODE PENELITIAN}

Lokasi dalam penelitian di kecamatan Kendit kabupaten Situbondo selama 1 bulan. Lokasi penelitian dipilih secara sengaja (purposive) dengan pertimbangan bahwa kecamatan Kendit juga menggunakan Inseminasi Buatan dalam usaha ternaknya. Metode yang digunakan dalam penelitian ini lebih mengarah pada metode deskriptif dan analitis. Penelitian deskriptif adalah suatu metode penelitian yang dilakukan dengan tujuan utama untuk membuat gambaran atau deskriptif tentang suatu keadaan secara objektif.

Penelitian ini menggunakan rumus Slovin karena dalam penarikan sampel, jumlahnya harus representative agar hasil penelitian dapat digeneralisasikan dan perhitungannya pun tidak memerlukan tabel jumlah sampel, namun dapat dilakukan dengan rumus dan perhitungan sederhana. Rumus Slovin untuk menentukan sampel adalah sebagai berikut :

$$
\mathrm{n}=\frac{N}{1+N(e)^{2}}
$$

Keterangan:

$\mathrm{n}=$ Ukuran sampel/jumlah responden

$\mathrm{N}=$ Ukuran populasi

$\mathrm{e}=$ Presentase kelonggaran ketelitian kesalahan pengambilan sampel yang masih

bisa ditolerir; $\mathrm{e}=0,1$

Dalam rumus Slovin ada ketentuan sebagai berikut:

Nilai e $=0,1(10 \%)$ untuk populasi dalam jumlah besar.

Nilai e $=0,2(20 \%)$ untuk populasi dalam jumlah kecil. 
Jumlah populasi dalam penelitian ini sebanyak 225 peternak, sehingga persentase kelonggaran yang digunakan adalah 10\%. Maka untuk mengetahui sampel penelitian dengan perhitungan sebagai berikut :

$\mathrm{n}=\frac{225}{1+225(0.01)^{2}}$

$\mathrm{n}=\frac{225}{3,25}=69,23$; disesuaikan oleh peneliti menjadi 69 responden

Selanjutnya akan dilakukan dengan metode pengambilan sampel cluster untuk memperkuat jumlah responden di setiap desa. Rumus cluster sebagai berikut :

Tabel 1. Cluster Sampling

\begin{tabular}{|c|c|c|}
\hline Desa & Populasi & Sampel \\
\hline Kendit & 18 & 6 \\
\hline Balung & 72 & 22 \\
\hline Bugeman & 13 & 4 \\
\hline Klatakan & 70 & 21 \\
\hline Kukusan & 25 & 8 \\
\hline Tambak Ukir & 27 & 8 \\
\hline Total & 225 & 69 \\
\hline
\end{tabular}

Analisis yang digunakan dalam penelitian ini yaitu regresi linier berganda. Analisis Regresi Linier Berganda adalah regresi linier untuk menganalisis besarnya hubungan dan pengaruh variabel independen yang jumlahnya lebih dari dua (Suharyadi dan Purwanto, 2004).

Adapun persamaan model regresi berganda tersebut adalah (Suharyadi dan Purwanto, 2011) :

$$
Y=a+b_{1} X_{1}+b_{2} X_{2}+b_{3} X_{3}+b_{4} X_{4}+b_{5} X_{5}
$$

Keterangan:

$\begin{array}{ll}\mathrm{Y} & : \text { Penggunaan IB (kali) } \\ \mathrm{X}_{1} & : \text { umur (tahun) } \\ \mathrm{X}_{2} & \text { : pendidikan (tahun) } \\ \mathrm{X}_{3} & : \text { jumlah keluarga (jiwa) } \\ \mathrm{X}_{4} & \text { : intensitas penyuluhan (kali) } \\ \mathrm{X}_{5} & \text { : pengalaman beternak (tahun) } \\ \mathrm{a} & \text { : nilai konstanta } \\ \mathrm{b}(1,2,3,4,5) & \text { : nilai koefisien regresi }\end{array}$

Guna menguji apakah keseluruhan variabel independen memberikan pengaruh pada variabel dependen digunakan uji F dengan formulasi sebagai berikut:

Kriteria pengambilan keputusan :

$$
\text { F-hitung }=\frac{\text { Kuadrat Tengah Regresi }}{\text { Kuadrat Tengah Sisa }}
$$

a. F-hitung $\leq$ F-tabel (10: 0.05 ), berarti keseluruhan variabel independen tidak memberikan pengaruh pada penggunaan IB (variabel dependen).

b. F-hitung > F-tabel (目圆= 0.05), maka menolak H0, berarti keseluruhan variabel independen memberikan pengaruh pada penggunaan IB (variabel dependen). 
Untuk mengetahui pengaruh masing-masing variabel bebas terhadap variabel tetap maka dilanjutkan dengan uji-t. Menurut Suharyadi dan Purwanto (2011) untuk menentukan nilai t-hitung maka dengan cara :

$$
\text { t hitung }=\frac{b-B}{S b}
$$

Dimana :

$$
\begin{array}{ll}
\text { t-hitung } & =\text { besarnya } \text { t-hitung } \\
\mathrm{b} & =\text { koefisien regresi } \\
\mathrm{Sb} & =\text { standar error }
\end{array}
$$

Kriteria pengambilan keputusan :

a. $\mathrm{t}$-hitung $\leq \mathrm{t}$-tabel $(\propto=0,05)$, maka variabel independen tidak memberikan pengaruh yang nyata pada variabel dependen.

b. t-hitung $>$ t-tabel $(\propto=0,05)$, maka variabel independen memberikan pengaruh yang nyata pada variabel dependen.

\section{HASIL DAN PEMBAHASAN}

\section{Karakteristik Peternak Pengguna IB berdasarkan Jenis Kelamin}

Responden yang menjadi subjek pada penelitian ini adalah peternak yang menggunakan IB dan dipilih berdasarkan acak sederhana berjumlah 69 peternak. Berikut sebaran responden berdasarkan jenis kelamin :

Tabel 2. Karakteristik Responden Berdasarkan Jenis Kelamin

\begin{tabular}{clcc}
\hline No & \multicolumn{1}{c}{ Jenis Kelamin } & Frekuensi & Persentase \\
\hline 1. & Perempuan & 22 & 31,9 \\
\hline 2. & Laki-laki & 47 & 68,1 \\
\hline & Total & $\mathbf{6 9}$ & $\mathbf{1 0 0 , 0}$ \\
\hline
\end{tabular}

Sumber : Data diolah tahun 2018

Berdasarkan data yang disajikan dalam tabel 2 dapat diketahui bahwa responden dalam penelitian ini terdiri dari perempuan $(31,9 \%)$ dan laki-laki $(68,1 \%)$. Berdasarkan hasil tersebut dapat dinyatakan bahwa sebagian besar responden dalam penelitian ini adalah laki-laki.

\section{Hasil Analisis Data Peternak Responden}

Berikut adalah faktor-faktor yang mempengaruhi peternak sapi potong terhadap intensitas penggunaan IB :

\subsection{Peternak Responden Berdasarkan Umur}

Dibawah ini merupakan tabel peternak responden berdasarkan umur adalah sebagai berikut :

Tabel 3. Peternak Responden Berdasarkan Umur

\begin{tabular}{ccc}
\hline Interval Umur (Tahun) & Responden (Orang) & Persentase (\%) \\
\hline $36-42$ & 26 & 37,7 \\
$43-49$ & 25 & 36,2 \\
$50-56$ & 18 & 26,1 \\
\hline Total & 69 & 100,0 \\
\hline
\end{tabular}

Berdasarkan tabel 3 dapat diketahui bahwa persentase peternak responden yang paling tinggi berada pada interval 36 - 42 tahun yaitu sebesar 26 orang atau 37,7\%. Umur berpengaruh dalam pengambilan keputusan yang tepat dan pengalaman beternak. Hal ini mendukung optimalisasi kerja peternak responden, karena keberhasilan usaha ternak 
sapi potong ditentukan oleh pengambilan keputusan yang tepat dan pengalaman dalam beternak sapi potong.

\subsection{Peternak Reponden Berdasarkan Pendidikan}

Berdasarkan pendidikan, dibawah ini adalah tabel peternak responden berdasarkan pendidikan yaitu sebagai berikut :

Tabel 4. Peternak Responden Berdasarkan Pendidikan

\begin{tabular}{clcc}
\hline No & Jenis Pendidikan & Jumlah Reponden (Orang) & Persentase (\%) \\
\hline 1 & SD & 9 & 13,0 \\
2 & SMP & 38 & 55,1 \\
3 & SMA & 22 & 31,9 \\
\hline \multicolumn{2}{r}{ Jumlah } & 69 & 100,0 \\
\hline
\end{tabular}

Berdasarkan tabel 4 dapat diketahui bahwa rata-rata peternak responden telah menempuh jenjang pendidikan hingga tingkat SMP dengan jumlah responden sebanyak 38 orang atau 55,1\%. Jenjang pendidikan akan menentukan peternak dalam berfikir dan bertindak rasional yang didukung dengan pengetahuan dan kemampuan untuk saling bertanya kepada sesama peternak dalam memecahkan sebuah masalah.

\subsection{Peternak Responden Berdasarkan Jumlah Keluarga}

Berdasarkan jumlah keluarga, dibawah ini adalah tabel peternak responden berdasarkan jumlah keluarga yaitu sebagai berikut :

Tabel 5. Peternak Responden Berdasarkan Jumlah Keluarga

\begin{tabular}{ccc}
\hline Jumlah Keluarga (Orang) & Responden (Orang) & Persentase (\%) \\
\hline 4 & 34 & 49,27 \\
5 & 32 & 46,38 \\
6 & 3 & 4,35 \\
\hline Total & 69 & 100,00 \\
\hline
\end{tabular}

Berdasarkan tabel 5 dapat diketahui bahwa rata-rata peternak responden memiliki jumlah keluarga 4 orang sebanyak 34 responden atau 49,27\%. Jumlah keluarga akan menentukan peternak dalam menjalankan usaha ternak agar mampu memenuhi kebutuhan hidupnya.

\subsection{Peternak Responden Berdasarkan Intensitas Penyuluhan}

Berdasarkan intensitas penyuluhan, dibawah ini adalah tabel peternak responden berdasarkan intensitas penyuluhan yaitu sebagai berikut :

Tabel 6. Peternak Responden Berdasarkan Intensitas Penyuluhan

\begin{tabular}{ccc}
\hline Intensitas Penyuluhan (Kali) & Responden (Orang) & Persentase (\%) \\
\hline 5 & 3 & 4,35 \\
6 & 18 & 26,07 \\
7 & 20 & 29,00 \\
8 & 21 & 30,43 \\
9 & 7 & 10,15 \\
\hline Total & 69 & 100,00 \\
\hline
\end{tabular}

Berdasarkan tabel 6 dapat diketahui bahwa rata-rata peternak responden menerima penyuluhan sebanyak 8 kali dengan jumlah responden sebanyak 21 responden atau $30,43 \%$. Intensitas Penyuluhan akan menentukan peternak dalam menerapkan suatu 
teknologi budidaya peternakan yang dapat meningkatkan keuntungan peternak dan mutu benih yang lebih baik lagi.

\subsection{Peternak Responden Berdasarkan Pengalaman Beternak}

Berdasarkan pengalaman beternak, dibawah ini adalah tabel peternak responden berdasarkan pengalaman beternak yaitu sebagai berikut :

Tabel 7. Peternak Responden Berdasarkan Pengalaman Beternak

\begin{tabular}{ccc}
\hline $\begin{array}{c}\text { Interval Pengalaman Beternak } \\
\text { (Tahun) }\end{array}$ & Responden (Orang) & Persentase (\%) \\
\hline $11-13$ & 10 & 14,49 \\
$14-16$ & 25 & 36,23 \\
$17-19$ & 28 & 40,58 \\
$\leq 20$ & 6 & 8,70 \\
\hline Total & 69 & 100,00 \\
\hline
\end{tabular}

Berdasarkan tabel 7 dapat diketahui bahwa rata-rata peternak responden memiliki pengalaman beternak antara 17-19 tahun dengan jumlah responden sebanyak 28 responden atau 40,58\%. Pengalaman beternak akan menentukan peternak dalam mengambil keputusan untuk mencari jalan keluar terhadap masalah-masalah dalam menjalankan usaha ternaknya.

\subsection{Peternak Responden Berdasarkan Jumlah Ternak}

Berdasarkan jumlah ternak, dibawah ini adalah tabel peternak responden berdasarkan jumlah ternak yaitu sebagai berikut :

Tabel 8. Peternak Responden Berdasarkan Jumlah Ternak

\begin{tabular}{ccc}
\hline Jumlah Ternak (Ekor) & Responden (Orang) & Persentase (\%) \\
\hline 1 & 1 & 1,45 \\
2 & 24 & 34,78 \\
3 & 22 & 31,88 \\
4 & 16 & 23,19 \\
5 & 6 & 8,70 \\
Total & 69 & 100,00 \\
\hline
\end{tabular}

Berdasarkan tabel 8 dapat diketahui bahwa rata-rata peternak responden memiliki jumlah ternak 2 ekor dengan jumlah responden sebanyak 24 responden atau $34,78 \%$. Jumlah ternak akan menentukan peternak dalam menjalankan usaha ternaknya agar diperoleh keuntungan yang tinggi.

\subsection{Peternak Responden Berdasarkan Penggunaan IB}

Berdasarkan penggunaan IB, dibawah ini adalah tabel peternak responden berdasarkan penggunaan IB yaitu sebagai berikut :

Tabel 9. Peternak Responden Berdasarkan Penggunaan IB

\begin{tabular}{ccc}
\hline Interval Penggunaan IB (Kali) & Responden (Orang) & Persentase (\%) \\
\hline $8-10$ & 21 & 30,43 \\
$11-13$ & 34 & 49,28 \\
$14-16$ & 14 & 20,29 \\
Total & 69 & 100,00 \\
\hline
\end{tabular}


Berdasarkan tabel 9 dapat diketahui bahwa rata-rata peternak responden telah menggunakan IB sebanyak 11-13 kali dengan jumlah responden sebanyak 34 responden atau $49,28 \%$. Penggunaan IB akan membuat peternak mengetahui bagaimana manfaat IB terhadap usaha ternaknya.

\section{Faktor-faktor yang Mempengaruhi Peternak Sapi Potong Terhadap Intensitas Penggunaan Inseminasi Buatan yaitu Umur, Pendidikan, Jumlah Keluarga, Intensitas Penyuluhan, Pengalaman Beternak dan Jumlah Ternak.}

Faktor-faktor yang diduga mempengaruhi peternak dalam penggunaan Inseminas Buatan di Kabupaten Situbondo adalah Umur (X1), Pendidikan terakhir (X2), Jumlah Keluarga (X3), Intensitas Penyuluhan (X4), Pengalaman Beternak (X5) dan Jumlah Ternak (X6). Untuk menguji hipotesis pertama dengan 69 responden sebagai berikut :

Pengujian faktor-faktor yang berpengaruh terhadap penggunaan IB tersebut menggunakan model fungsi linier berganda sebagai berikut :

$\mathrm{Y}=2,426+0,048 \mathrm{X} 1-0,076 \mathrm{X} 2-0,336 \mathrm{X} 3+0,942 \mathrm{X} 4-0,007 \mathrm{X} 5+0,896 \mathrm{X} 6$

Berikut ini merupakan tabel analisis varian (ANOVA) faktor-faktor yang mempengaruhi peternak sapi potong dalam penggunaan IB di kabupaten situbondo.

Tabel 10. Analisis Varian (ANOVA) Faktor-faktor yang Mempengaruhi Peternak Sapi Potong dalam Penggunaan Inseminasi Buatan di Kabupaten Situbondo

\begin{tabular}{|c|c|c|c|c|c|c|}
\hline \multirow{2}{*}{\multicolumn{7}{|c|}{$\begin{array}{l}\text { ANOVA }^{\mathrm{a}} \\
\mathrm{df} \quad \text { Mean Sauare }^{2}\end{array}$}} \\
\hline & Model & Sum of Squares & $\mathrm{df}$ & Mean Square & $\mathrm{F}$ & Sig. \\
\hline \multirow[t]{3}{*}{1} & Regression & 191,258 & 6 & 31,876 & 25,210 &, $000^{\mathrm{b}}$ \\
\hline & Residual & 78,395 & 62 & 1,264 & & \\
\hline & Total & 269,652 & 68 & & & \\
\hline
\end{tabular}

a. Dependent Variable: Penggunaan IB

b. Predictors: (Constant), Jumlah Ternak, Pengalaman Beternak, Pendidikan Terakhir, Jumlah Keluarga, Umur, Intensitas Penyuluhan

Berdasarkan tabel 10 diatas Pengujian dengan uji $\mathrm{F}$ bertujuan untuk melihat keseluruhan variabel bebas memberikan pengaruh pada variabel terikat. Hasil analisis pada tabel 9 diperoleh nilai F-hitung sebesar 25,210 lebih besar dari F-tabel sebesar 2,25 pada taraf kepercayaan 95\%. Hasil tersebut menunjukkan bahwa secara bersama-sama variabel bebas (umur, pendidikan terakhir, jumlah keluarga, intensitas penyuluhan, dan pengalaman beternak) berpengaruh terhadap penggunaan IB sebagai variabel terikat.

Besarnya parameter faktor-faktor yang berpengaruh terhadap penggunaan IB dapat diketahui melalui nilai determinasi (R2). Koefisien determinasi berfungsi untuk mengetahui berapa persen pengaruh yang diberikan variabel $X$ secara simultan terhadap variabel Y. Berikut ini adalah nilai determinasi (R2) yang dapat dilihat pada tabel 11.

Tabel 11. Nilai Determinasi (R2) Model Summary

\begin{tabular}{lrrrr}
\hline Model & \multicolumn{1}{l}{ R } & R Square & Adjusted R Square & Std. Error of the Estimate \\
\hline 1 &, $842^{\mathrm{a}}$ &, 709 &, 681 & 1,124 \\
\hline
\end{tabular}

a. Predictors: (Constant), Jumlah Ternak, Pengalaman Beternak,

Pendidikan Terakhir, Jumlah Keluarga, Umur, Intensitas Penyuluhan

Berdasarkan output pada tabel 11 menunjukkan nilai Adjusted R Square sebesar 0,565. Nilai tersebut menunjukkan bahwa pengaruh variabel X1, X2, X3, X4, X5 dan X6 secara simultan terhadap varibel Y yaitu sebesar 68,1\%. Penggunaan IB di Kabupaten Situbondo dipengaruhi oleh variabel bebas (umur, pendidikan terakhir, jumlah keluarga, intensitas penyuluhan, pengalaman beternak, dan jumlah ternak) sebesar 68,1\%. Sedangkan sisanya 31,9\% dipengaruhi oleh variabel-variabel lain yaitu keberhasilan IB 
dan pelayanan Inseminator yang tidak dimasukkan dalam model regresi. Tingkat keberhasilan IB yang berdasar pada data Dinas Peternakan Dan Kesehatan Hewan Kabupaten Situbondo menunjukkan bahwa sapi yang berhasil di IB dengan pelaksanaan 1 kali suntikan saja sebanyak 59 ekor, sedangkan sapi yang berhasil di IB dengan pelaksanaan 2 kali suntikan sebanyak 10 ekor. Dari data diatas menunjukkan tingkat keberhasilan IB sebesar 85,5\%. Pelayanan Inseminator terhadap peternak juga sangat baik. Pelaksanaan Inseminasi dilakukan dengan mengunjungi peternak sapi secara langsung sehingga peternak merasa puas terhadap pelayanan Inseminator karena lebih mudah dalam berkonsultasi mengenai ternaknya.

Untuk mengetahui pengaruh masing-masing variabel bebas terhadap variabel terikat dilakukan dengan uji-t dimana hasil dari analisis regresi linier berganda dapat dilihat pada tabel 12 .

Tabel 12. Analisis Regresi Linier Berganda Terhadap Faktor-faktor yang Mempengaruhi Peternak Sapi Potong dalam Penggunaan IB di Kabupaten Situbondo.

Coefficients ${ }^{\mathrm{a}}$

\begin{tabular}{|c|c|c|c|c|c|c|}
\hline \multirow[b]{2}{*}{ Model } & & \multicolumn{3}{|r|}{$\begin{array}{c}\text { Standardized } \\
\text { Coefficients }\end{array}$} & \multirow[b]{2}{*}{$\mathrm{t}$} & \multirow[b]{2}{*}{ Sig. } \\
\hline & & B & Std. Error & Beta & & \\
\hline 1 & (Constant) & 2,426 & 1,812 & & 1,339 & 186 \\
\hline & Umur & ,048 & ,031 & 125 & 1,528 & 132 \\
\hline & $\begin{array}{l}\text { Pendidikan } \\
\text { Terakhir }\end{array}$ & -,076 & ,074 &,- 074 & $-1,030$ & ,307 \\
\hline & Jumlah Keluarga &,- 336 & 281 &,- 098 & $-1,193$ & ,237 \\
\hline & $\begin{array}{l}\text { Intensitas } \\
\text { Penyuluhan }\end{array}$ & ,942 & 160 &, 504 & 5,886 & ,000 \\
\hline & $\begin{array}{l}\text { Pengalaman } \\
\text { Beternak }\end{array}$ &,- 007 & ,060 &,- 009 & -113 & 910 \\
\hline & Jumlah Ternak & ,896 & ,162 & ,450 & 5,540 & ,000 \\
\hline
\end{tabular}

a. Dependent Variable: Penggunaan IB

Berdasarkan hasil output pada tabel 12 diatas, dapat diketahui bahwa konstanta dari analisis tersebut sebesar 2,426 artinya bahwa sebelum peternak dipengaruhi oleh faktor-faktor variabel X1, X2, X3, X4, X5 dan X6, peternak telah menggunakan IB sebanyak 2 kali.

Pengaruh variabel bebas (umur, pendidikan terakhir, jumlah keluarga, intensitas penyuluhan, dan pengalaman beternak) terhadap variabel terikat (penggunaan IB) adalah sebagai berikut :

\section{Umur (X1)}

Nilai koefisien regresi umur adalah sebesar 0,048 yang artinya bahwa setiap peningkatan umur sebesar 1 tahun dalam interval umur 36-56 tahun, maka penggunaan IB meningkat sebesar 4,8\% dalam satu kali produksi dengan asumsi faktor lainnya tetap.

Dari hasil analisis uji-t menunjukkan bahwa besarnya nilai t-hitung $(1,528)$ lebih kecil dari t-tabel $(1,99962)$, berarti bahwa faktor umur peternak tidak memberikan pengaruh yang nyata terhadap penggunaan IB. Hal ini didiukung oleh Swastha dalam skripsi Muhammad Yusuf (2016) yang menyatakan bahwa tingkat produktifitas kerja seseorang akan mengalami peningkatan seiring dengan pertambahan umur dan akan 
kembali menurun pada saat menjelang tua. Menurut pernyataan diatas bahwa umur hanya mempenngaruhi tingkat produktifitas seseorang namun tidak mempegaruhi seseorang dalam menggunakan IB. Hal ini dikarenakan peternak yang berumur muda maupun tua jika sudah memperoleh penyuluhan tentang IB dan memiliki jumlah ternak yang banyak, maka juga akan meningkatkan penggunaan IB.

\section{Pendidikan Terakhir (X2)}

Nilai koefisien regresi pendidikan terakhir adalah sebesar -0,076 yang artinya bahwa setiap peningkatan pendidikan sebesar 1 tahun, maka akan menurunkan penggunaan IB sebesar 7,6\% dalam satu kali produksi dengan asumsi bahwa faktor lainnya tetap. Hal tersebut dikarenakan peternak yang berpendidikan terakhir tinggi tidak selalu memiliki jumlah ternak yang banyak, sehingga penggunaan IBnya juga sesuai dengan jumlah ternak yang dimiliki peternak responden.

Dari hasil analisis uji-t menunjukkan bahwa besarnya nilai t-hitung $(-1,030)$ lebih kecil dari t-tabel $(1,99962)$, berarti bahwa faktor pendidikan terakhir peternak tidak memberikan pengaruh yang nyata terhadap penggunaan IB. Hal ini sesuai dengan Hasbullah (2009) yang menyatakan bahwa pendidikan adalah usaha yang dijalankan oleh seseorang atau kelompok orang lain agar menjadi dewasa atau mencapai tingkat hidup atau penghidupan yang lebih tinggi dalam arti mental. Namun pendidikan tidak mempengaruhi penggunaan IB yang artinya peternak yang memiliki pendidikan rendah maupun tinggi sama-sama dapat menggunakan IB, karena dengan adanya penyuluhan tentang IB memberi pengetahuan kepada peternak tentang inovasi budidaya ternak yang tidak akan diperoleh dipendidikan formal.

\section{Jumlah Keluarga (X3)}

Nilai koefisien regresi jumlah keluarga yaitu sebesar -0,336 yang artinya setiap peningkatan jumlah keluarga sebanyak 1 orang, maka akan menurunkan penggunaan IB sebesar 33,6\% dengan asumsi bahwa faktor lainnya tetap. Hal tersebut dikarenakan peternak yang berjumlah keluarga banyak tidak selalu memiliki jumlah ternak yang banyak pula, sehingga penggunaan IBnya juga sesuai dengan jumlah ternak yang dimiliki peternak responden.

Dari hasil analisis uji-t menunjukkan bahwa besarnya nilai t-hitung $(-1,193)$ lebih kecil dari t-tabel $(1,99834)$, berarti bahwa faktor jumlah keluarga tidak memberikan pengaruh yang nyata terhadap penggunaan IB. Hal ini sesuai dengan Sumbayak (2006) yang menyatakan bahwa jumlah keluarga adalah salah satu faktor ekonomi yang perlu diperhatikan dalam menentukan pendapatan untuk memenuhi kebutuhannya. Namun untuk penggunaan Inseminasi Buatan tidak dipengaruhi oleh jumlah keluarga yang banyak ataupun sedikit, tetapi dipengaruhi oleh jumlah ternak yang dimiliki peternak, semakin banyak jumlah ternak maka akan berpotensi menggunakan IB yang lebih tinggi pula.

\section{Intensitas Penyuluhan (X4)}

Nilai koefisien regresi intensitas penyuluhan yaitu sebesar 0,942 yang artinya setiap peningkatan intensitas penyuluhan sebanyak 1 kali, maka akan meningkatkan penggunaan IB sebesar $94,2 \%$ dengan asumsi bahwa faktor lainnya tetap.

Dari hasil analisis uji-t menunjukkan bahwa besarnya nilai t-hitung $(5,886)$ lebih besar dari t-tabel $(1,99834)$, berarti bahwa hipotesis yang diajukan yaitu faktor intensitas penyuluhan mempengaruhi penggunaan IB secara nyata diterima. Sehingga faktor intensitas penyuluhan memberikan pengaruh yang nyata terhadap penggunaan IB. Hal ini didukung oleh Sumbayak (2006) yang menyatakan bahwa Semakin sering mengikuti penyuluhan maka keberhasilan penyuluhan peternakan yang disampaikan semakin tinggi 
pula. Sehingga tingkat intensitas penyuluhan yang tinggi akan memberikan pengaruh yang tinggi pula terhadap penggunakan IB.

\section{Pengalaman Beternak (X5)}

Nilai koefisien regresi pengalaman beternak adalah sebesar -0,007 yang artinya setiap peningkatan pengalaman beternak sebesar 1 tahun, maka akan menurunkan penggunaan IB sebesar 0,7\% dengan asumsi bahwa faktor lainnya tetap. Hal tersebut dikarenakan peternak yang memiliki pengalaman beternak lama tidak selalu memiliki jumlah ternak yang banyak, sehingga penggunaan IBnya juga sesuai dengan jumlah ternak yang dimiliki peternak responden.

Dari hasil analisis uji-t menunjukkan bahwa besarnya nilai t-hitung $(-0,113)$ lebih kecil dari t-tabel $(1,99834)$, berarti bahwa faktor pengalaman beternak tidak memberikan pengaruh yang nyata terhadap penggunaan IB. Hal ini sesuai dengan Wati, et al (2010) yang menyatakan bahwa peternak yang memiliki pengalaman beternak yang cukup lama umumnya memiliki pengetahuan yang lebih banyak dibandingkan peternak yang baru saja menekuni usaha peternakan. Namun pengalaman beternak yang sedikit maupun yang lama sama-sama dapat menggunakan IB dalam usaha ternaknya karena adanya penyuluhan peternakan tentang IB yang memberi pengetahuan kepada peternak mengenai teknologi budidaya sapi potong guna meningkatkan populasi.

\section{Jumlah Ternak (X6)}

Nilai koefisien regresi jumlah ternak yaitu sebesar 0,896 yang artinya setiap peningkatan intensitas penyuluhan sebanyak 1 kali, maka akan meningkatkan penggunaan IB sebesar 89,6\% dengan asumsi bahwa faktor lainnya tetap.

Dari hasil analisis uji-t menunjukkan bahwa besarnya nilai t-hitung $(5,540)$ lebih besar dari t-tabel $(1,99834)$, berarti bahwa hipotesis yang diajukan yaitu faktor jumlah ternak mempengaruhi penggunaan IB secara nyata diterima. Sehingga faktor jumlah ternak memberikan pengaruh yang nyata terhadap penggunaan IB. Hal ini dikarenakan penggunaan IB tergantung dari jumlah ternak yang dimiliki oleh peternak. Semakin banyak jumlah ternak yang dimiliki, maka semakin tinggi pula potensi peternak yang akan menggunakan IB.

\section{KESIMPULAN DAN SARAN}

Berdasarkan hasil analisis dan pembahasan, maka dapat diambil beberapa kesimpulan yaitu :

1. Faktor-faktor yang mempengaruhi peternak sapi potong dalam penggunaan IB yaitu umur, pendidikan terakhir, jumlah keluarga, intensitas penyuluhan, dan pengalaman beternak sebesar $68,1 \%$, sedangkan sisanya $31,9 \%$ dipengaruhi oleh variabel-variabel lain yaitu keberhasilan IB dan pelayanan Inseminator yang tidak dimasukkan dalam model regresi.

2. Berdasarkan analisis uji t, faktor intensitas penyuluhan memiliki nilai t-hitung $(5,886)$ lebih besar dari t-tabel $(1,99962)$. Sehingga intensitas penyuluhan memiliki pengaruh secara nyata terhadap penggunaan IB.

\section{REFERENSI}

Anonim. 2016. Menteri Luncurkan UPSUS SIWAB (Sapi Indukan Wajib Bunting). Lamongan.

Idfar. 2017. Diagnosa Kebuntingan Dini Dalam Mendukung Tingkat Keberhasilan Inseminasi Buatan Sapi Bali Di Kecamatan Manggelewa Kabupaten Dompu. 
Hasbullah. 2009. Dasar-Dasar Ilmu Pendidikan. Jakarta : Raja Grafindo Persada.

Suharyadi dan Purwanto. 2004. Statistika Dasar. Jakarta: Salemba Empat.

2011. "Statistika untuk Ekonomi dan Keuangan Modern Edisi 2". Jakarta : Salemba Empat.

Sumbayak. 2006. Karakteristik Peternak. Cekza Blog : Bogor.

Wati, et al. 2010. Analisis Faktor - Faktor Yang Mempengaruhi Pendapatan Peternak Ayam Ras Petelur Di Kecamatan Lareh Sago Halaban Kabupaten Lima 50 Kota. Fakultas Peternakan. Universitas Andalas. Padang. 